\title{
A new socio-philosophical model of leadership needed
}

\author{
Tanha Mahjabeen \\ Curtin University, Australia \\ onlytanha18@yahoo.com
}

\begin{abstract}
In the new millennium, most of the people are suffering from cynicism regarding the character and role of the leaders. They have adverse feelings about the controversial activities of leaders. Situation is much worse in the developing nations, where Bangladesh is also an example. Political leaders are often considered as the only leaders here. Unfortunately, the political leaders are mostly corrupted and selfcentered. They only try to mislead the nation to achieve their own heinous goals. Following such pseudo leaders as role models and consequently observing the deformation of social values can affect the personality formation of the young generation of the nation. If such practices continue, a better future can never be expected.
\end{abstract}

This paper addresses the gravity of the situation and emphasizes the emergence of new leaders in the sociopolitical situation at the grass-root level in the urgent need of the day. It describes the model of a leader who can mobilize the common people to meet their legitimate, strategic and basic needs and interests which ultimately leads to the promotion of development and preservation of resources by planning and optimizing consumption. The paper indicates that such types of true leaders should have the ability to challenge any problematic process, inspire and enable people to work for greater good, sacrifice his personal benefit and achieve any targeted goal.

The fundamental practices of exemplary leadership have been explained for the construction of a good model for effective leaders in this paper. The practices those have been discussed here are: to be pragmatic and people focused, practicing strategic modesty, being good to words, ensuring justice and peace, having qualified followers etc. These characteristics of the connotation of leadership seem to be more suitable for the new millennium in order to build a sustainable future involving the state and the community.

A true leader who will be able to lead a nation successfully will also be able to help in emerging thousands of other true leaders. However, each individual of the community will have to strive for that. In this way the whole world will be free from the crisis of leadership.

Keywords: Leadership, Community, Characteristics, Practices, Planning. 


\section{PSEUDO-LEADERSHIP IN BANGLADESH}

In this modern world with lives full of problems and complexities, leaders should be the ones who can show people right way and hope. In times of any calamity they should appear as the comfort zones for the helpless general people. Unfortunately, just the opposite thing is happening around the world today, especially in the underdeveloped and the developing nations (Cohen, 2010). Bangladesh, being a developing nation is no exception to it. Political leaders are often considered as the only leaders in the country. In most cases they are powerful and influential in a negative way. The positive qualities of an effective leader are totally absent among such leaders. Because of their negligent tendencies they themselves appear as the big problems for the nation instead of safeguarding it (Haque, 2007). Their only target is to achieve their personal benefit no matter what it may cost the nation. In the absence of real leaders they occupy the platform in a wrong manner.

The so-called leaders have some followers who are always busy in flattering them. They are not aware of the famous saying: "The tongues of flatterers are like daggers in our absence, but in our presence, softer than silk" (Gaer, 1956: 114). According to them, their leader posses the best qualities of a human being and are doing the right thing. They will have a gang of followers to attend the procession, enchanting slogans and organize meetings. A meeting of a leader is successful if it is being attended by a large number of people, the type of people attended is hardly considered as important. Such Political leaders have no communication and interaction with the common people of Bangladesh. They collect subscriptions from the local traders. Consequently the politician and the business person have a close affinity. Business people having black money receive support from the political leader because they donate money for their party. As the leaders are influential they try to influence different government offices in the wrong manner. These types of leaders force the office to give jobs to their party members through the back door. They give shelter to the criminals of their own party. They try to take all advantage from the society by influencing and exerting their power and exploiting the ignorant. Some leaders nurture young gang stars and hoodlums for their defense. They use them to teach a good lesson to the opponent party. The gang stars are known as 'cadre' of the political party (Khan 1984). These Leaders are busy in delivering long speeches with endless unrealistic promises to the people which they never fulfill. Despite common people's mistrust, they cannot protest out of fear.

These leaders shed crocodile tears for the rural poor while leading in luxurious life in the city. Holzhausen rightly said: "Highly educated leaders have lost touch with their poorer urban and rural compatriots and they may know very little about the real needs and aspirations of the people. Attempts to reform from above often fail because they ignore the real needs of the masses or tend to contravene local traditions and thus lack popular support" (Holzhausen, 1986: 8). These leaders use local students to cause agitation, strike and thus create session jam delaying their educational degrees but their own children study abroad safely. If any of their mischievous activities of them were exposed to the people they would never apologize. For all evil they will make responsible the opponent party whereas credit they demand for all good things done. They have no accountability to the people whom they represent. These leaders increase the number of their followers with giving financial and other privileges in the wrong manner. This leadership crisis is moving the socioeconomic development of the country in a negative direction. In the 2003 national seminar of the Bangladesh Economics Association on "The Political and Economic Profile of Bangladesh: Where we are Going, Where to Go", keynote speaker said, "People are trapped under criminalization of politics ... now we need insightful courageous patriotic leadership accomplished with high humane values and substantive public action" (Barkat, 2003).

A democratic leader's aim should be to establish equality and fraternity but in the practical field we observe mutual hatred, naked rivalry, jealousy prevailing among the leaders of Bangladesh. Votes are purchased by money. The findings from a 2004 study in Bangladesh reveal that: "Leaders spent huge money (at least $5,00,000$ BDT) for election. So after election they try to recollect the money from the people. How can we expect good work from them?" (Ara, 2004: 8). The narrow interest for occupying political power leads the leaders to bribe the people by any means. Most of the messages of the leaders are deceptive and misleading. This shameless naked propaganda has the cumulative effect of encouraging dishonest, corrupt and inefficient leaders.

Nowadays leaders believe in egoistic hedonism service which means service for their own pleasure and enjoyment. Sometimes their enjoyment reminds us of the Carvaka morality (Gargi, 2000) of eating expensive tasty food even when taking loans. Altruism is totally absent. However a leader is morally bound to perform service for the community. A true leader should believe the motto of Stuart's Utilitarianism. Stuart in his famous book 'Utilitarianism' states that the greatest happiness of the maximum number of 
people is the ultimate end of human action (Stuart, 1992). His utility or happiness is the outcome of right and wrong that has been drawn from the idea of justice. "Idea of justice implies two components: a rule of conduct, and a sentiment which sanctions the rule. The first is intended for the good of the people. The 'sentiment' is the desire that punishment may be suffered by those who infringe the rule" (Stuart, 1992: 36). The first of judicial virtue, impartiality is an obligation of justice, but in practice we observe that the notions of neutrality, equality and impartiality are converted into different meaning.

The followers who belong to the leader's organization are blindly supported by the leader even if they are involved in a criminal offence. To defend one's own follower and offend the followers of another leader is the only motto. Justice in the higher scale of social utility is written only in black and white. Many leaders try to increase the number of followers by giving them undue advantages in various fields ignoring competent candidates outside their organization or party. The lack of social justice is one of the major causes for a leadership crisis. The leaders abuse their legitimate power, exceed its limits and neglect its proper exercises. Innocent people suffer from a 'leader-phobia'. It is even found that leaders can be elected by showing their tyrannical power and muscles in a community. "That politics is a dangerous business and that no politician could afford failure that in the political arena survival of the strongest, or most ruthless, was the order of the day" (Holzhausen, 1986: 8).

Following such pseudo-leaders as role models and observing the deformation of social values, the personality formation of the young generation are totally affected. A number of alarming facts emerge: crime among youth being on increase, a greater part of educated and dropout youths being unprepared to participate in real life, skepticism on the rise among young people, estrangement from the ideals of society, pursuit of social activities outside social life such as drug addiction, following the pop and punk culture etc. All these depict serious perturbation in personal value systems.

When there is a discrepancy between ideals and reality, formalism on the part of elders engenders the upbringing of young people in deep personal conflict. On the one hand, they are torn between what is inherent in the age as they strive towards fulfillment in the "adults' world", and on the other hand, there a negation of the concrete patterns found in the ideals and negative role models. This causes feelings of insecurity and alienation from actual social life. The striving towards social activity is expressed in informal groups formed by young people on the basis of common interests and activities and is oriented towards an alternative way of life which may not be socially acceptable.

\section{A MODEL OF IDEAL LEADERSHIP NEEDED FOR BANGLADESH}

The vast majority of the Bangladeshi people are living below the poverty line. They are in the worst conditions physically, psychologically and socially. We do not have sufficient food and clothing, adequate housing and minimum health facilities. Population growth as well as child and maternal mortality rates are very high (BBS, 2006). Violence, terrorism, crime, bloody party conflicts of the political parties are on increase (Stahl, no date). Unemployment is the most alarming problem of the youth. Justice and people's participation in the development process are almost absent. The financial systems are so full of embezzlement that it turns out that the poor are providing subsidies to the rich. Despite of all this difficulties our family bond is based on sharing and caring which indicates that the positive sides of our culture have not been abolished yet (Moula, 2002). But serious political problem is the main reason that is not letting the country move forward. According to Peiris (1998) political conflict has caused people deprivation in the last three decades. All we need now is a good leader who can fight against all perils created by the so called political leaders who have turned politics into a profit-making business. We seek leaders who are bold enough to expose the social and political mask of the corrupt leaders; capable to organize young people from the grass-rook level. Social and community leaders who will emerge from the grass-root level working with common people shall believe the age long heritage and traditional roles of Bangladesh and consider the people as human beings. They should not be crazy to hold a big position or to be a parliamentary member or minister (Rahman, 1988). Genuine leaders are needed who will ensure justice by setting up good governance.

Asian people have age long cultural tradition which provides a rich reservoir of wisdom, virtue and strong identity. It is also true that all traditional cultures are not positive heritage. Patriarchy, gender discrimination, apathy for manual labour, dowry, begging as a profession, bribing and many other social prejudice which are rooted in our society are the dark side of our culture. If self-sufficiency is desired, genuine leaders have to be created who have commitment for real development of the people and bring evolutionary change in the existing power structure created by the corrupt leaders. Development is not only economic development but a considerable balance of socio-economic, moral and cultural development which will ensure genuine 
human development. Revitalization of creativity and sustainability is very important. Similarly development cannot be achieved only through western know-how and financial grant. Leaders should visualize the holistic vision of development which will synthesize eastern morality with western technology. Their mission would be to build new community, in order to have a full human life for the people.

According to Vivekananda, one of the great leaders of India, three make the good leader - conviction in the power of goodness, absence of jealousy and suspicion, and helping all who are trying to be and do well (Vivekananda, 2001). A leader must accept opposition view in a rationalistic manner. A leader must also accept opposing views in a rationalistic manner as each "who thinks ahead of his time is sure to be misunderstood" (Vivekananda, 2001: 47).

The strategic role of youth is important in this aspect. Some role models are needed to guide the young generation and train them to be disciplined and rational through leadership training. Politics is not isolated from people's life. A genuine leader is the advocate of social reform. Confrontation, rat-race competition and exploitation need to be avoided by the leader while harmony, unity and communality of share and care are to be encouraged. This socio-philosophical leader should not be dominated by the materialistic values of capitalism, the militaristic values of some western power and the techno-scientific values of western culture. People expect from an effective leader assurance of a broad-based system of social security, equitable distribution of income and wealth and meeting the basic need of life. Though it seems to be a utopia it is possible gradually.

The Five Fundamental Practices of Exemplary Leadership identified by Kouzes and Posner (Kouzes and Posner 1995) will be a good model for effective leaders in the new millennium.

Leaders challenge the process. Leaders do not accept the things as they are. They challenge the current status and believe that things can be different. In every single successful leadership case we find involvement of some kind of challenge. It may have been an innovative new creation or may be a protest against contemporary social unjust. Not one person claimed to have done his or her personal best by keeping things the same. In short, all leaders challenge the process. In the new millennium the socio-economic and psychological problem of the people are more complex. There is radical change in scientific discovery and information technology. So the leader should be ready to take risk to innovate and experiment in order to find new and better ways of doing things.

Leaders inspire a shared vision. The leaders have visions and dreams of what could be. To enlist people in a vision, leaders must know their stakeholders, speak their language and convey the message to other people. Every organization, every social movement, begins with a dream for the future. The dream or vision is the force that invents the future. Leaders have a desire to make something happen, to change the way things are, to create something that no one else has ever created before, so the leader must inspire a shared vision.

Leaders enable others to act. Exemplary leaders enlist the support and assistance of all those who can make the difference. Leaders proudly discuss teamwork, trust and empowerment as essential elements of their efforts. They know that no one does his or her best when feeling weak, incompetent or alienated. Leaders mobilize the people to come up from inertia. They know that those who are expected to produce the results must feel a sense of ownership. Leadership is a relationship, founded on trust and confidence. Without trust and confidence, people don't take risks. Without risks, there's no change. Without change, organizations and movements are bound to die.

Leaders model and mould the way. Leaders go first. Leaders model the way through the personal example and dedicated execution. Mother Teresa herself participated in the service of the sick people. To model effectively, leaders must first be clear about their guiding principles. Leaders are supposed to stand up for their beliefs, so they better have some beliefs to stand up for. Eloquent speeches about common values aren't nearly enough. Leader's deeds are far more important than their words and must be consistent with them. A leader must be a genuine role model for the followers. Leaders encourage the heart of the people. It is the part of the leaders' task that they can win. Leaders encourage the heart of their people to carry on. Genuine acts of caring can uplift the spirits and draw people forward.

True leader is an achiever. Self-reliance and personal competence provide the prerequisite to self-respect and success. Believing that success depends on personal achievement in the front lines of services, work leaders understand that what we know propels individual progress in a society founded on the ideals of pluralistic democracy. In the present world situation where every leader must work and every worker must 
lead, the motto becomes "If I fail, we fail, if we fail, I fail". The 'we' feeling is a precondition for successful team work.

\section{PRACTICES TO FULFILL THE SOCIO-PHILOSOPHICAL MODEL FOR LEADERSHIP}

A leader must be pragmatic and not think in an unrealistic manner. Thomas Edison was a pragmatist (Murphy, 1997). When it comes to selecting engineers he'd give the applicant a light bulb and ask: "How much water will it hold?" Most candidates would calculate the bulb's volume mathematically, an approach that takes twenty minutes or more. The smart ones, however would fill the bulb with water and then pour its contents into a measuring cup, a procedure that took less than one minute. Edison hired the engineer who worked in a pragmatic way. Like Edison, contemporary work leaders should realize that pragmatism is requirement for achievement i.e. willingness to ask questions and to search openly and without bias for practical answers to the most vexing problems. Work leaders use pragmatic questioning as an effective strategy for leadership for two reasons. Commonsense is an essential prerequisite of leadership. Common sense, it has been said, is the most uncommon thing in the world but it is the most democratic of all mental qualities. It is the combination of experience with intelligence. Sometimes leaders who live in a fool's paradise lose the ability to use experience to mould circumstances. Practical wisdom applied to common life is an essential attribute of genuine leadership. In the practical solution of community problems judgment based on common sense can work whereas theories and bookish knowledge may make it more complicated.

Effective leaders should be people focused. They should be "by the people for the people". They must be empathetic and sympathetic to the suffering of people. Leaders must participate in community service which fosters moral development. However this should not be done for the sake of publicity and publishing in the newspaper. Young people who will be the future leaders of a country can develop moral attitude and behavior from the training and practicing in the community. Morality does not arise accidentally. Its adoption depends on commitment. The leader has to make dialogue with the people. Dialogue allows researching and communicating at the same time. It not only generates the data you need to make an informed decision but communicates what we stand for in our personal commitment to gaining understanding and insight. According to the great architect and pragmatic Frank Lloyd Wright (Murphy, 1997: 17): "Form must follow functions. They have to learn to experiment and withhold judgment until they have objectively assessed the situation and identify a well-reasoned course of action".

Strategic modesty should be practiced. Nowadays a leader is characterized a rough crazy and agitated person (Rahman, 1988). Mature and intelligent leaders with practical knowledge seem to be rare. Strategic humility results from a strategic decision to use learning as a tool for progress, and it characterizes confident and assertive leaders. The recognition of the truth that the awareness of one's ignorance grows experimentally with one's knowledge should be accepted by the leader. A leader will be a continuous learner. The pseudoleaders seem to be the wisest people in the country as they are not eager to learn anything. They always talk and deliver long speeches but they never listen to learn from other people. A leader must be pleasing personality, humorous, smiling, pleasant, accessible and devoid of a bureaucratic rigid nature. We also expect our leaders to be enthusiastic, energetic and positive about the future. We expect them to be inspiring - a bit of the cheerleader, as a matter of fact. A leader must be able to communicate the vision in ways that encourage us to sign on for the duration. To enlist in another's cause, we must believe that the person is competent to guide us where we are headed. We must see the leader as capable and effective. If we doubt the leader's abilities, we are unlikely to enlist in the crusade. Expertise in leadership skills is another dimension of competence. Also the abilities to challenge, inspire, enable, model and encourage must be demonstrated, if leaders are to be seen as capable. A survey on characteristic of admired leaders conducted in Asia, Western Europe, Australia and North America on 20,000 people revealed that honest, forwardlooking, inspiring, and competent are the qualities consistently selected by all respondent groups as the four most essential leadership prerequisites (Kouzes and Posner, 1995). While these four qualities have remained at the top of the list over the decades of the study, the relative importances of forward-looking and inspiring ability have increased over time. By comparison, in many countries of the world the dishonest corrupt leaders drive the organization as well as the nation to destruction. In Bangladesh the dishonest, corrupt and incompetent leaders are dragging the nation to backward way.

Consistency between word and deed is how we judge someone to be honest. If leaders preach one set of values but personally practice another, followers find them to be deceitful. If leaders practice what they preach, people are more than willing to entrust them without caring for their security and sometimes even their life. In practice, leaders are found who perform the opposite of what they preach. For becoming a genuine leader a correct assimilation of knowledge, virtue and respect is needed. According to Aristotle, "Virtue is a permanent state of mind, formed with the concurrence of the will and based upon an ideal of 
what is best in actual life an ideal fixed by reason" (Aristotle, 1949: 36). Virtue is an indicator of good character. A leader must be a virtuous person whose aim to keep his desires in control. Aristotle's virtuous leader is neither a coward nor a rash person who invites dangers; but instead brave and enterprising. A leader should not run away leaving the followers in danger. Starting from the time of Confucius, the "agreement of one's words with one's deeds" has always been used as an ethical criterion to differentiate a noble person from a villain.

Leaders must ensure justice and equality. Just as Rosmini (1996: 426) said: "The leading principle of social progress is justice maintained coherently". He felt the need of social benevolence which consists in the good desired for the whole society. A leader must possess this quality. Plato in his Republic portrayed his notion of state, "the constitution of the state depends upon the nature of the soul, and political justice is but the outward expression of that inward harmony of soul in which true justice consists" (William, 1962: 45). About the virtue of perfect state Plato said that the sole being 'perfectly good' must possess four virtueswisdom, courage, temperance and justice. Wisdom is a special virtue of the rule for those who are leaders to administrate the state. Nowadays all the above qualities are totally absent in the notion of the leaders. What we observe in real life is a dark cloud of injustice covering the social and political sky; hypocrites, flatterers in the name of the leader occupy the privileged situation through which they do not deserve. Deserving people with intrinsic qualities are deprived of all such positions. They are being punished. 'Chairs' as a status symbol is misused. The irrational behavior of the leader improperly washed away the real meaning of justice.

Peace not war should be the slogan of a leader. War-hysteria, through application of power is not leadership. It is the disgrace of humanity. Leaders should maintain peace and reject war. A wrong decision by a leader is to start a war to destroy the humankind. A leader should know the skill of peaceful conflict-resolution. Unfortunately our leaders neither accept others' disagreement with respect nor show their different view peacefully. It is very natural to have discrepancy among different leaders' mission and vision but they have to argue rationally. The effective leader must seek peaceful resolution of conflict through striving for the fair settlement of personal and social conflicts, avoiding physical and verbal aggression. Confucius explained it long ago: "The superior man will be agreeable even when he disagrees; the inferior man will be disagreeable even when he agrees" (Gaer, 1956: 107).

The motive and intention of the leader are very important. Leadership should be based on the good will. A real leader will plead for a society in which all the constructive tendencies of human beings, love, cooperation and empathy may be allowed to develop to the maximum. The running of the social, economic, industrial and political institutions by the leaders should be based on cooperation rather than authority or force. Human are not only physical and psychological beings but also axiological beings. Values constitute an important part of human nature. Any person should not be used by the leader as a means of self interest. In human character moral will is the absolute good and the absolute and intrinsic value. "Nothing can possibly be conceived in the world, or even out of it, which can be called well without qualification, except a good will" (Mackenzie, 1961: 104). This means a good will is good not only because it yields something precious but also because its emergence within itself was divine. Such intension will remain good even if it is not fully successful in achieving its goal.

Followers are the most important factor in leadership because they have the potential of a leader. Conscious and educated followers can act as constructive critics for the leaders just the way a proper leader can help the followers to go thorough right direction. If the followers are foolish, ignorant and un-educated it is easy to misguide them. This is happening nowadays. As the large section of the people are uneducated in the developing countries, ignorance and lack of civic education hinder them to utilize their democratic right properly. So they have a tendency towards 'hero' worship. Leaders take advantage of blind faith of the followers and 'hero' worship continues. So there is need for education for ensuring effective leadership. Emergence of genuine leader cannot be expected if the general mass is not properly educated. Democracy is inconceivable without education, because education can generate and instill the qualities which democracy demands as a prerequisite. Until the ground for democracy is set up through educating people how can we expect the creation of democratic leadership? Education of the followers does not mean the bookish or higher education which helps to earn a living. It should be preparation of life. Through innovative teaching methods that respect and nurture the individuality and creativity of students, it integrates the physical, emotional, intellectual and spiritual aspects of their growth in a well-rounded program. Teaching students to embrace their common humanity is to recognize their place in the web of life. Education for creating morally matured persons is needed. Systematic, planned, theoretically grounded and conscientiously sustained moral education must be included in the curriculum of both formal and non-formal education. Moral education is indispensable in a democratic society because a government by the people requires that the people be 
good - that they have at least a minimum understanding and commitment to the moral values on which a democracy rests.

\section{CONCLUSION: PLANNING FOR THE FUTURE}

We expect our leaders to have a sense of direction and a concern for the future of the organization. This expectation directly corresponds to the ability to envision the future. Vision is the magnetic north that provides others with the capacity to chart their course toward the future.

Grounded in philosophical, psychological and social principles, the integrated paradigm of leadership affirms the necessity of taking a unified conception and application in the community and state. It is urgently needed to rekindle a working relationship among politicians, civil society, teachers, bureaucrats, students, non-students and the general mass. Only a genuine leader can achieve this; otherwise the conflict and dirty rivalry among different political parties, exploitation of the poor in the hands of rich will continue. Effective leaders should be judged by their performance, sincerity, commitment and by the progress achieved in increasing the nation's good governance material welfare and in maintaining as large as possible a degree of personal liberty in the country. The socio-philosophical and moral leader can use an effective model for cultivating character building among the youth and set up a paradigm of leadership for the future generation. Leadership is not a monopoly of some persons. With the light of leadership qualities socio-philosophical leader will light thousands of candles of leadership.

\section{REFERENCES}

Ara, R. (2004). Knowledge, Attitude and Practices, National Survey on Democracy and Governance of Bangladesh, pp. 8. Centre for Management Consulting Survey Research Group (SRG) Bangladesh Ltd.

Aristotle (1949), The Ethics of Aristotle, Trans. by D. P. Chase, pp. 36. J. M. Dent and Sons Ltd., New York. Bangladesh Bureau of Statistics (BBS) (2006). Statistical Pocketbook of Bangladesh 2004, Bangladesh Bureau of Statistics, Dhaka.

Barkat, A. (2003). The Political and Economic Profile of Bangladesh: Where we are going, where to go. Paper presented at National Seminar, Bangladesh Economics Association, Dhaka, Bangladesh.

Cohen, W. A. (2010). Heroic leadership: leading with integrity and honor. Calif.: Jossey-Bass, San Francisco.

Gaer, J. (1956). The Wisdom of the Living Religions, pp. 114. Dodd, Mead and Company, New York.

Gargi, J. (2000). Morality and Religion. Anmol Publications Ptv. Ltd. India.

Haque, A.H. (2007). Local Leadership: Development, Problems and Potential in Bangladesh, The Asia

Pacific Journal of Public Administration, 29 (2), 223-239.

Holzhausen, W. (1986). Vision Creates Hope, Reflections on Development Issues in Developing Countries and in Bangladesh, pp. 8. The University Press Ltd., Bangladesh.

Khan, Z. R. (1984). Leadership Crisis in Bangladesh, University Press Limited, Bangladesh.

Kouzes, J. M. and B. Z. Posner (1995). The Leadership Challenge, Jossey Bass Publishers, San Francisco.

Mackenzie, C. (1961). A Mamual of Ethics, pp. 104. University Tutorial Press Ltd, $6^{\text {th }}$ edition.

Moula, Q. (2002). In Positive Image of Bangladesh, The Bangladesh Today, December 20.

Murphy, E. C. (1997). Leadership. John Wiley and Sons Inc. New York.

Peiris, G. H. (1998). Political Conflict in Bangladesh, Ethnic Studies Report. XVI (1), 178-181.

Rahman, A. (1988). "Rural Touts and Power Structure in Bangladesh: Some Indicative Results of a Perception Survey of the Patronage Network". ADAB News, XV (4).

Rosmini, A. (1996). The Philosophy of Rights: Rights in Civil Society, Trans. By D. Cleary and T. Watson, 6, pp. 426. Rosmini House, Durham.

Stahl, A. E. (No date) Challenges Facing Bangladesh. Global Politics. Accessed on 27 July 2011, http://www.global-politics.co.uk/issue\%203/Bangladesh.htm

Stuart, M. J. (1992) Utilitarianism, J.M. Dent Ltd., London.

Vivekananda (2001). Advatic Ashrama, pp.47. Publication Department, India.

William, B. (1962). An lntroduction to the Republic of Plato, pp. 45. George Allen and Unwin Ltd., London. 